(昭和 36 年 4 月 4 日受理)

酢酸七几口一不溶液 の粘度的研究

第 4 報三酢酸セルロース漕厚溶液の粘度

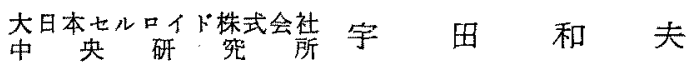

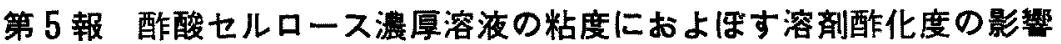

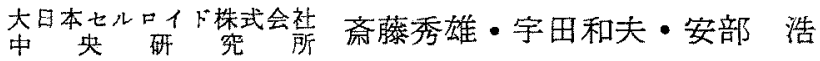

\section{VISCOSITY STUDIES OF CELLULOSE ACETATE SOLUTIONS (IV) (V)}

\section{(IV) VISCOSITIES OE CELLULOSE TRIACETATE CONCENTRATED SOLUTIONS}

By Kazuo Uda

(Central Research Laboratory, Dainippon Celluloid Co. Ltd., Öimura, Iruma-gun, Saitama Prefecture, Japan)

Viscosities of cellulose triacetate solutions were determined and the relations between viscosity, concentration and d. p. were tested.

The samples were from purified cotton linters and wood pulps and their acetyl contents and d.p. were $60.0 \sim 60.8 \%$ and ca. $200 \sim 390$, respectively.

The solvents used were the mixture of methylene chloride-methanol, $9: 1$ by weight and the concentration ranges were $13 \sim 18 \%$.

In the ranges of concentration and d.p. tested the relations between viscosity $(\eta)$, concentration $(C)$ and d.p. $(P)$ were as follows:

$$
\text { and } \quad \begin{aligned}
\log \eta & =K C+A \\
\log \eta & =k P+a
\end{aligned}
$$

where $K, k$ and $A, a$ are constants.

It was also found that the viscosities of cellulose triacetate from purified wood pulps are higher than those of purified cotton linters.

\section{(V) EFFECTS OF THE SOLVENTS AND THE DEGREE OF ACETYLATION ON THE VISOSITIES OF CONCENTRATED SOLUTIONS OF CELLULOSE ACETATE}

By Hideo Saito, Kazuo Uda and Hiroshi Abe

(Central Research Laboratory, Dainippon Celluloid Co. Ltd., Öimura, Iruma-gun, Saitama Prefecture, Japan)

Viscosities of three cellulose acetate flakes (acetyl contents, 60.6, 57.3 and 51.1\%) in the mixed solvents of methylene chloride-methanol at $18 \%$ concentration at $25^{\circ} \mathrm{C}$ were measured by falling ball method, and the effects of the methanol contents $(1 \sim 50 \%)$ in the mixed solvents upon the viscosities of these concentrated solutions of cellulose acetate differing in the acetyl contents were investigated.

It was found that the methanol contents have the marked influences on the solution viscosities: and there are the definite methanol contents for each sample that give the minimum viscosities values.

The higher the acetyl contents of cellulose acetate, the smaller the amounts of methanol corres- 
ponding to the minimum viscosities and also the less markedly the changes of viscosities near the minimum values.

These phenomena are briefly discussed with referrence to the behavior of the intrinsic viscosities of various kinds of cellulose acetate in these mixed solvents systems previously reported by one of the authors').

(Received April 4, 1961)

\section{第 4 報 三酶酸セルロース濃厚溶液の粘度}

\section{1. 緒言}

アセトン可溶性の第二次酢酸セルロール(酢化度 54.0 〜56.0\%) については，そのアセテート繊維としての古 い歴史から肴薄括よび濃厚アセトン溶液について多くの 知見がえられているが、近年トリアセテート紻維として， また不然性フィルムベースとして，工業的他市眅される 上うになつた三酶酸セルャース（以下 TAC と略記, 酸 化度60.0〜62.5\%) の溶液物性については，希薄溶液に ついてもまたことに濃厚溶液についてもあまり報告さ れていない。著者らは前報りに招いて，主としてメチレ ンクロライドーアルニール系泿合溶剂による希薄溶液の 粘度について報告したが，本報では工業的に紡糸あるい は成膜時に寒用されるような濃厚溶液について，まず落 球法による静的粘度を測定し，TACの重合度，濃度と 粘度との関保をしらべた。

また第二次アセテート（SAC）のアせトン溶液では， 一般にパルプベースの方がリンターベースの SAC より 高い粘度を与えることが示されているので, TAC のメ チレンクロライド系混合剂溶液についても，そのよ5な 差違がみとめられるかどうかについても，一部検討を行 なつた。

\section{2. 実 験 方 法}

\section{1 試 料}

精製リンダーあるいは精製木材パルプを原料として， 無水酢酸一酢酸一硫酸系混酸により常法に従い，酢化，熟

第 1 表 三酢酸セルロース試料の性状

\begin{tabular}{c|c|c|c|c|c}
\hline 試料 No. & 酢酸度 (\%) & 重合度 & 試料 No. & $\begin{array}{c}\text { 酢化度 } \\
(\%)\end{array}$ & 直合度 \\
\hline L-1 & 60.3 & 389 & L-8 & 60.3 & 303 \\
L-2 & 60.5 & 381 & L-9 & 60.5 & 291 \\
L-3 & 60.4 & 373 & L-10 & 60.4 & 268 \\
L-4 & 60.4 & 354 & P-1 & 60.4 & 304 \\
L-5 & 60.2 & 339 & P-2 & 60.7 & 299 \\
L-6 & 60.0 & 337 & P-3 & 60.6 & 284 \\
L-7 & 60.3 & 314 & P-4 & 60.3 & 247 \\
\hline
\end{tabular}

（註）L，Pはそれそれりンター拉よびパルプぶースをあ らわす。
成，安定化精製したものでめる。その分析性状を一括し て表 1 にしめしたが，酢化度は60.0〜60.7\%，重合度は $200 \sim 390$ 程度の TAC である。

\section{2 溶 剂}

メチレンタロライドーメタノールの $9: 1$ (重量比) 混 合溶剂を尃使用した。メチレンクロライドは $15^{\circ} \mathrm{C} の$ 比重1.320〜1.340，またメタノールは $15^{\circ} \mathrm{C} の$ 比重 0.798 以下のものを使用し，いずれも使用㡺前に常法により精 製した。

\section{3 溶液の調製}

試料はあらかじめ使用前に $100 \sim 105^{\circ} \mathrm{C} て ゙ ~ 3 \mathrm{hr}$ 乾燥 して絶乾としたものを精科して粘度湘定管（後述）にと り，溶解を坞一，讯速ならしめるためにまずょタノール で浸閏せしめたのち、メキレンクロライドを加完て密栓 して約 30 分間放置したのち，回転溶解機（5～50 rpm） で 24〜48hr 充分にかきまぜて完全に溶解せしめた。加 える各溶剤の量は、メチレンクロライドとメタノールの 比が $9: 1$ であり，かつ種々の TAC 濃度 (13〜18\%) になるよ5予的算して定めて拈く。

\section{4 粘度の測定}

大綱は ASTM-D871-54T Kよるが，若千の修正を行 なつたす法を採用した。要点のみ記載する。

粘度湘定管は内径 $50.8 \pm 1.5 \mathrm{~mm}$, 高さ $200 \mathrm{~mm}$ のた” ラス管で，底よりそれそれれ 25 拉よび，さらにそれより $63.5 \pm 0.5 \mathrm{~mm}$ の高さの所火刻線を付す。落球秒数測定 用鋼球は市販品より, 外径 $3.615 \sim 3.185 \mathrm{~mm}$, 重量 $0.1290 \sim 0.1320 \mathrm{~g}$ の規格に合格するるのを充らんで使用 した。

本報では粘度測定温度は $25 \pm 0.02^{\circ} \mathrm{C}$ 一定とし, 粘度 管の中心部に落下せしめた鋼球が刻印間 $(63.5 \mathrm{~mm})$ 落下なるに必要な秒数をよみとり，同一溶液について 4 〜 5 回これをくりかえしてその平均值をるつて落下秒数 とした。

落下秒数から絶対粘度への換算は Faxen の式尕により 行なら。すなかb

$$
\begin{aligned}
& \eta \text { ポイズ }=\frac{2 r^{2} g}{9 L}\left[1-2.104\left(\frac{d}{D}\right)+2.09\left(\frac{d}{D}\right)^{3}\right. \\
& \left.\quad-0.95\left(\frac{d}{D}\right)^{3}\right](b-\rho) t
\end{aligned}
$$


第 2 表 三酶酸七ルロースの粘度湘定結果

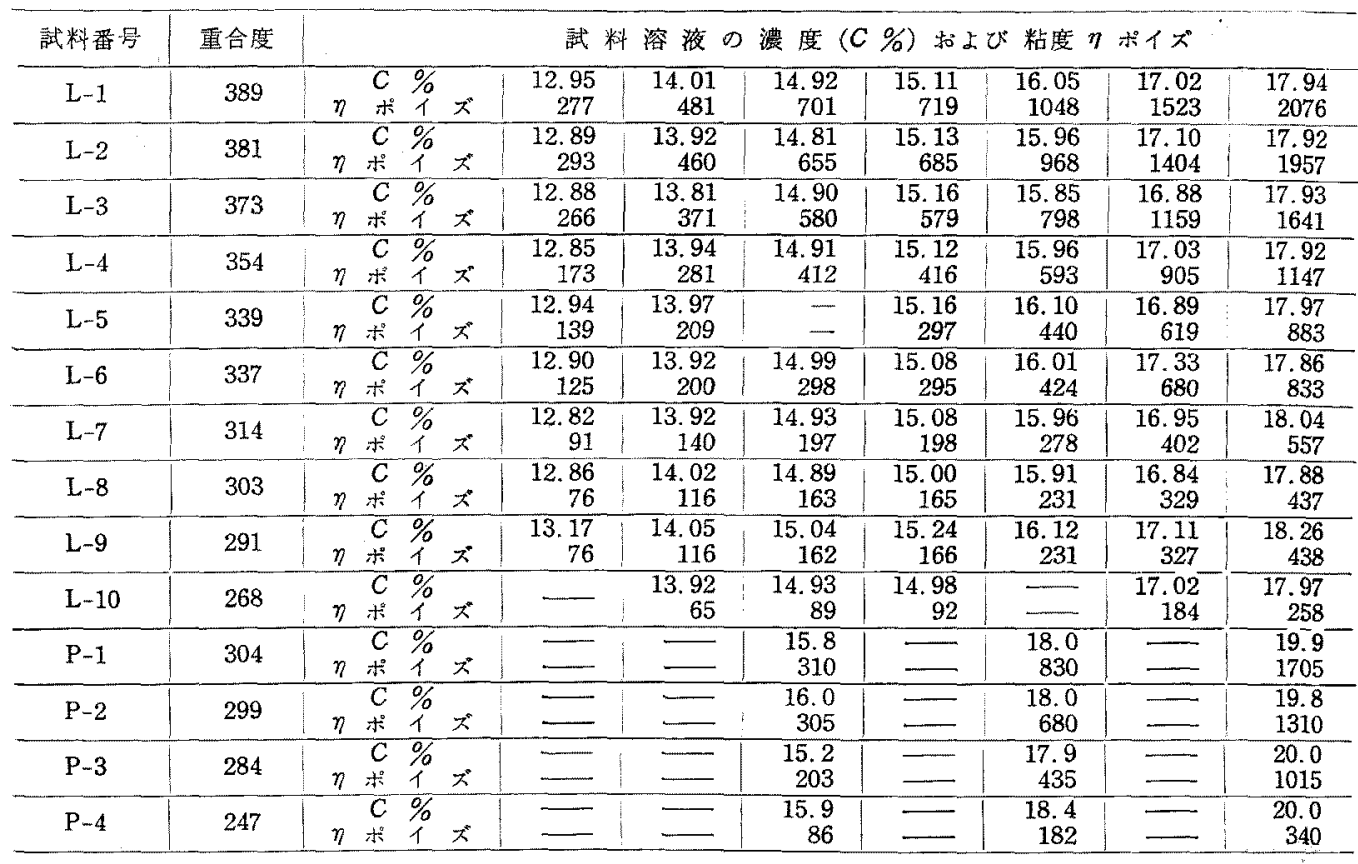

ただし， $g$ は重力の加速度， $\mathrm{cm} / \mathrm{sec}^{2}, r, d, D$ はそれ ぞれ球の半径括よび球, 粘度管の直径 $(\mathrm{cm}), L$ は落下距 離 $(6.35 \mathrm{~cm}) ， b$ 扣よび 0 はそれぞれ球敊よび溶液の密 度 $\left(\mathrm{g} / \mathrm{cm}^{3}\right)$ ，これらの装置常数值怙よび溶液の密度 $\rho=$ 1.24 (TAC の比重埾平均 1.30 として) の值を入れる 々, $\quad \eta=0.7510 \times(7.76-1.24) t=4.896 t$

(たたし $t$ は测定した落下秒数) として求めることがで
液の $K_{m}$ 值を $5.0 \times 10^{-4}$ として定めたことるすでにのへ t。

\section{3. 実験結果と考察}

粘度の測定結果をるとて表2にしめした。この5b リンターヘースの TAC (L 陚料) Kついて, $\log \eta \sim c$ のプロットをとつてみると图1のようにそれぞれの重合 ह。

\section{5 湄度の測定}

粘度測定を终つた溶液の一部を经射筒で，一

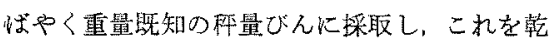

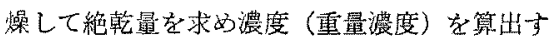
る。乾燥にあたつて，あらかじめ溶液に非溶剂 (いまの易合ふ夕ノ一ル) を適当量加えて半ば

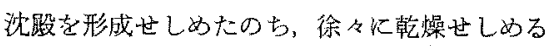
之，溶阂を残留世しめず，絶乾量を出すの化 効である。

\section{6 酿化度, 重合度の測定}

酰化度は A.S.T.M. D 871-46 Tとより求め た。また重合度は前報坛にり，試料のメチと ンクロライド,メタノール(9:1, 重量比) 溶液 に括ける極限粘度求め， $K_{m}=5.4 \times 10^{-4}$ とし て Staudinger の粘度式沈より算定した整定的 な值である。な抗この $K_{m}$ 值は七ルロ一ス銅安

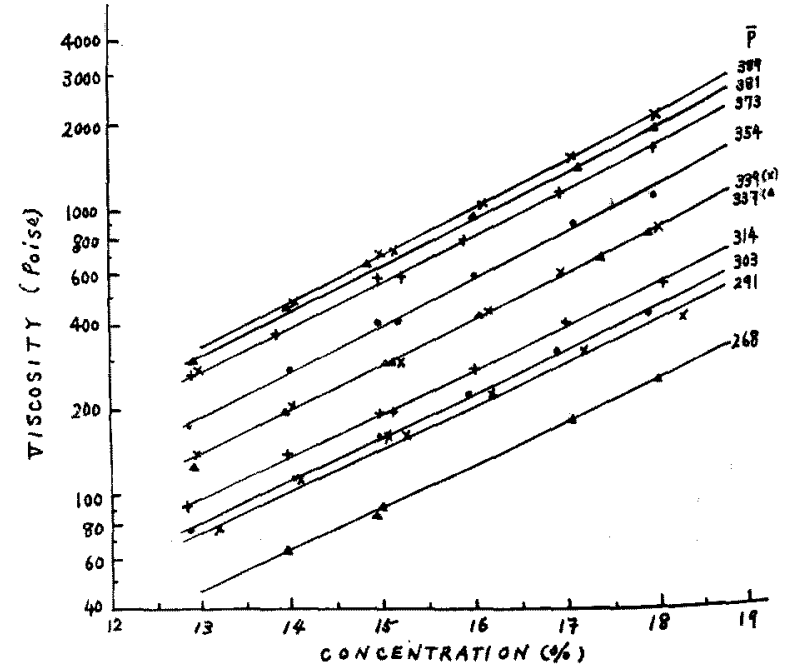

Fig1. Viscosity-cóncentration-DP relations. 
第 3 表

ソシターペース三酷酸セルロース粘度の濃度勾配値 $K$

\begin{tabular}{c|c|c|c|c|c|c|c}
\hline 重合度 & 268 & 291 & 303 & 337 & 354 & 373 & 381 \\
\hline$K$ & 0.148 & 0.150 & 0.152 & 0.157 & 0.162 & 0.165 & 0.164 \\
\hline
\end{tabular}

度について，ほぼ直線関係がみとめられ，粘度濃度の関 係式は次式でしめされる。

$$
\log \eta=K C+A
$$

ただし $K ， A$ はそれを゙れ恒数とする。

粘度と濃度との関係式については多くの実験式が提案 されているが，いずれる濃度の指数函度として表わされ る。Arrhenius ${ }^{3)}$ にり提案され, Ber1*), Duclaux 括よ び Wollmann ${ }^{5}$ によつて継承された有名な式として次式 がある。

$$
\begin{gathered}
\eta=\eta_{0} e^{K C} \\
\text { または } \quad \log \eta=K^{\prime} C+\log \eta_{0} \\
\eta, \eta_{0} \text { はをれぞれ溶液，溶斉の粘度とする。 }
\end{gathered}
$$

Papkov'はさらにこの式を一般化して次式を提案し t。

$$
\log \eta=K C^{\alpha}
$$

近年 Flory ${ }^{7}$ によボリエステルージエチルサタシネー ト采で站された次式も（3）に近い。

すなか方

$$
\log \eta=K W_{2}^{1 / 2}+\text { const. }
$$

たたし $W_{2}$ 恔質の重量分率で $\left(0.2<W_{2}<1.0\right)$ の とき（4）方成立する。乙かしこの（4）仙一般に成 立する例はすくないとされている。

本穾験の結果では，TACのメチレンタロライドーメタ ノールに上る濃厚溶夜では，測定した濃度，重合度の籍

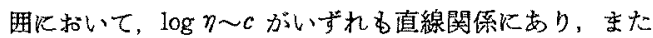
$\log \log \eta \sim \log c$ のプロットをとつて得られた直線(図省 略) の傾斜加占式（3）K上り求めた $\alpha$ の值も0.94 1.02の間に京つて，ほぼ1にひとしく，一般的にいつて (1) の式で粘度-濃度の関係式が与意られることをしめ している。

図1から各重合度每に直線の㑯斜を求め算出した $K$ 值

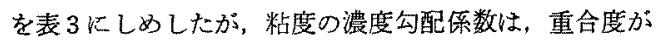
ひくい汪ど小さい值をとるが，厹の差は小さく，0.14〜 0.16 の間の值をしめしている。

パルプペースの場合は測定濃度の数がすくないがやは り同㴍に $\log \eta \sim c$ 㥀線にのり， $K$ 值がやや高いるうで あ。（园省略）

また図1の㗐線を利用して，各重合度について，各湍 度に和ける粘度をグラフ上で求めてみると表 4 の上うに なる。このようにして求めた粘度と重合度 ( $P$ とする) との関保を種なの濃度についてブロットすると区2のよ
第 4 表 三酢酸セルロースの各濃度に的ける 粘度と重合度との関係（単位：ポイズ）

\begin{tabular}{l|r|r|r|r|r|r|r}
\hline $\begin{array}{l}\text { 試料 } \\
\text { 番号 }\end{array}$ & 濃度(\%) & 13 & 14 & 15 & 16 & 17 & 18 \\
\hline L-1 & 389 & 330 & 485 & 700 & 1020 & 1500 & 2220 \\
L-2 & 381 & 315 & 460 & 660 & 940 & 1340 & 1950 \\
L-3 & 373 & 275 & 400 & 580 & 830 & 1200 & 1720 \\
L-4 & 354 & 195 & 282 & 410 & 590 & 840 & 1240 \\
L-5 & 339 & & & & & & \\
L-6 & 337 & 144 & 205 & 295 & 425 & 620 & 890 \\
L-7 & 314 & 98 & 140 & 198 & 280 & 400 & 560 \\
L-8 & 303 & 79 & 115 & 165 & 240 & 340 & 460 \\
L-9 & 291 & 70 & 100 & 146 & 210 & 300 & 410 \\
L-10 & 268 & 46 & 65 & 91 & 128 & 183 & 260 \\
P-1 & 304 & 98 & 146 & 220 & 340 & 520 & 790 \\
P-2 & 299 & 88 & 135 & 200 & 295 & 450 & 680 \\
P-3 & 284 & 72 & 103 & 150 & 220 & 320 & 470 \\
P-4 & 247 & 31 & 44 & 62 & 87 & 120 & 170 \\
\hline
\end{tabular}

うに $\log \eta \sim P$ の間にほぼ直線関係が成立するようであ $\eta, こ の$ 関係式を次式で表わす。

$$
\log \eta=k P+a
$$

ただし， $k, a$ は惿数となる。

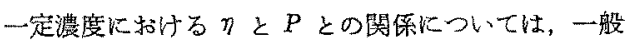
Kno $P \beta$ の留俰が提案され，Beuche ${ }^{8)}$ によば $\beta=3.4$ が高分子領域で，また低分子量のものに対しては $\beta$ は〜 1.5 とされている。したがつて $\log \eta \sim \log z$ のプロット はある分子量域で屈曲した直線になるわけであるが，い まの実験では分子量の範围がせまいのでこのような頵向 は明瞭ではなかつた。

図 2 から各濃度に括け吉粘度の重合度勾配值 $k$ 求め

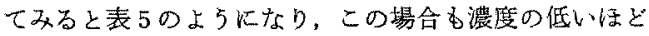

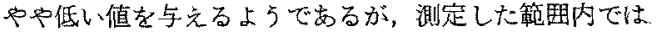
淟度による差の小さいことを亦している。

つぎに上と同じよらな方法でパルプベースの TAC に ついては舁測した粘度一濃度の関保から各濃度に括ける 粘度一重合度の関係を図上で求めた結果を比較のため表

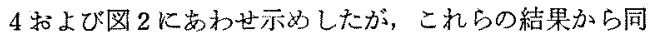

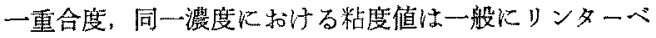
一スのものよりパルプベースのものが高いことが明らか であり，また先の勾配値も大きいようである。アせトン 可溶性の SAC でも一般にパルプベースの方が粘度が高

第 5 表

リンターベース・三酶酸せルロース粘度の重合度勾配值

\begin{tabular}{c|c|c|c|c|c|c}
\hline 濃度 & 13 & 14 & 15 & 16 & 17 & 18 \\
\hline$k \times 10^{3}$ & 7.40 & 7.32 & 7.60 & 7.70 & 7.80 & 7.90 \\
\hline
\end{tabular}


、多がその原因としては，パルプ 中のカルボキシル基などの変質基 飞上る塩類効果 ${ }^{10)}$ の外飞, へミセ ルロースなどの随伴不純物質の多 いこと，あるいは重合度分布の不 均一性などがあげられているが，

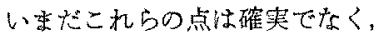
TAC の場合にこれらと同じょ らな原因火よるすのであらうが， SAC の場合をらくめて今後さら 㰸討を要する問題である。

\section{4. まとめ}

酢化度 $60.0 \sim 60.7 \%$ ，重合度 200 ～390 程度の三酷酸七ルロースの メチレンクロライド,メタノール (9:1, 重量比) 混合溶剂以上る 13〜 18\% 濃度の濃厚溶液粘度を 落球法见より湘定し，濃度重合度

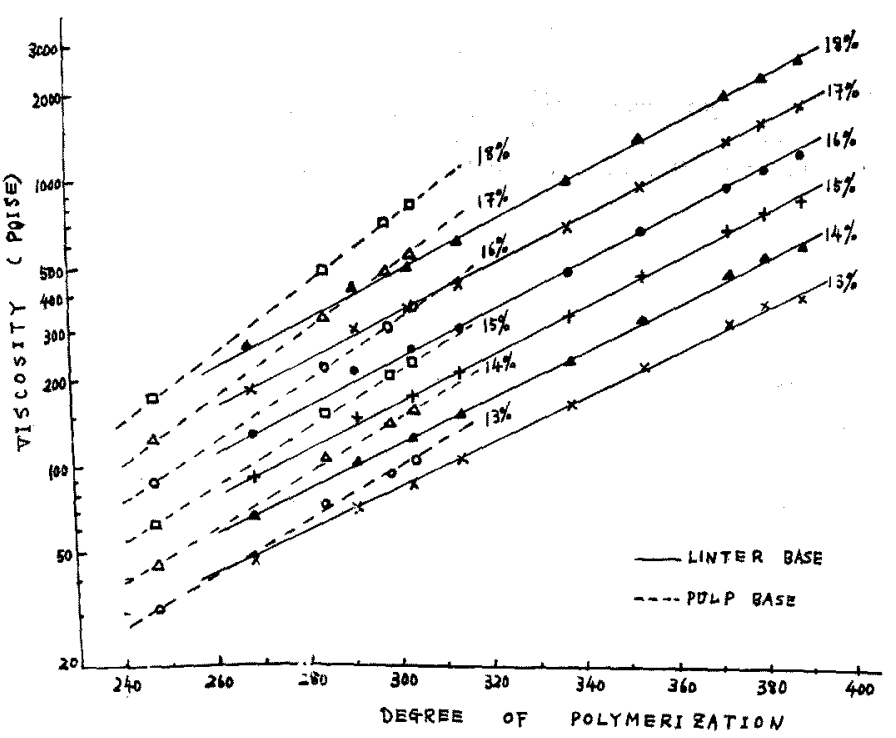

Fig 2. Viscosity-d. p. -concentration relations.
と粘度との間の閶係をしらべたが，これら测定した範网 内で、ほぼ次のよ5な比較的簢単な式で素現できるこ とをみとめた。

$$
\begin{aligned}
\log \eta & =K C+A \\
\text { 小よ。 } \quad \log \eta & =k P+a
\end{aligned}
$$

$\eta ， C Ｐ$ はそれぞれ粘度，濃度和上び重合度， $K ， k ， A$ ， $a$ 恒数とする。

つぎにパルプベース括よびリンダーベースの三瞃酸せ ルロースの粘度を比較したが，アセトン可溶性第二次ア せテート同様，パルプペースの方が粘度がより高いこと を双とめた。

（発表を許可された会社当局並に御指尊いただいた松田

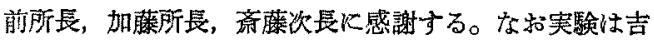
浦昭治君が行なつたもので，多わせてお礼申のベる次第 である）
文 献

1）著者；酷酸セルロース溶液の粘度的研究，策 2 報本 绫投稿中

2) C. J. Malm, L.B. Genung, G. B. Laharm; Anal. Chem, 22, 656 (1950)

3) Arrhenius; Z.physik, 1, 285 (1887)

4) Berl und Büttler; Z. Schiess und Sprengstoffwesen, 5, 82, (1920)

5) Duclaux et Wollmann; Compt. rendu., 152, 1580 (1911)

6) S.Papkov; Kunststoffe, 25, 253 (1935)

7) P.J.Flory; J.Phys. Chem., 46, 870 (1942)

8) F. Beuche;J .Chem. Phys., 20, 1959 (1952);ibid., 25, 599 (1956)

9) C1J. Malm; Suensk Papperstidn., 50, 135 (1947)

10) H.Engelmann; Das Papier, 5, 149 (1957)

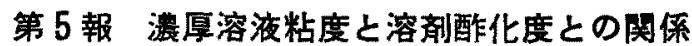

\section{1. 緒}

言

酢酸せルロースのメチレンクロライド・メタノール混 合溶剂による希薄溶液の粘度に関しては，著者の一人が 前報1に搔いて，メタノール含有量と酢化度とに上る極 根粘度の変化について検愔した結果を報告した。本報に

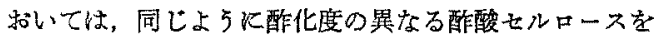
用いメチレンクロライド・メタノール系混合溶郕による 濃厚溶液に拈いて, メタノール含有量がその粘度に拉よ
ぼす影響について検討したのでその概要を報告する。

\section{2. 実 験 方 法}

実験に使用した試料の性状は第 1 表に記した通りで,

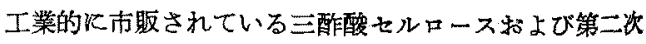
醀酸七ルロースならび酢化度がその中閣にあるような 試料計 3 種をるらいた。

これらの試料をメチレンクロライド,メタノール系混 